\title{
INTERNATIONAL JOURNAL OF RESEARCH IN SOCIAL SCIENCES \& HUMANITIES
}

\section{An International Open-Access Peer Reviewed Referred Journal}

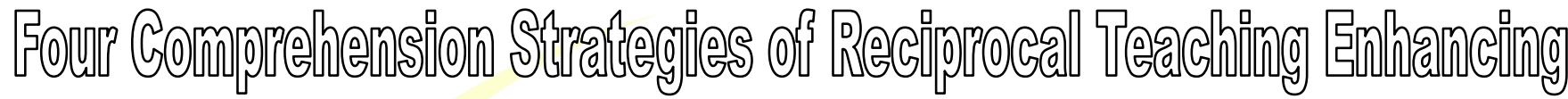

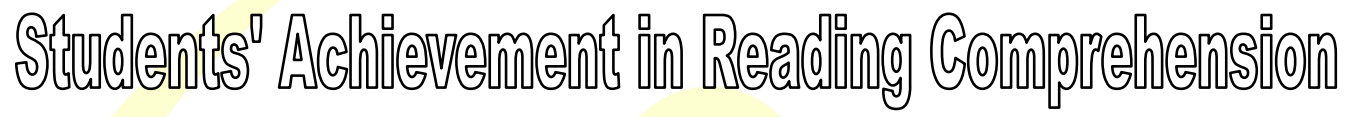

\section{*Hayfaa Kadhim Mohammed, **Afrah Abduljabbar Abdulsahib}

*College of Basic Education, English Department, Misan University, Iraq

**College of Education, English Department, Misan University, Iraq

DOI: http://doi.org/10.37648/ijrssh.v11i04.003

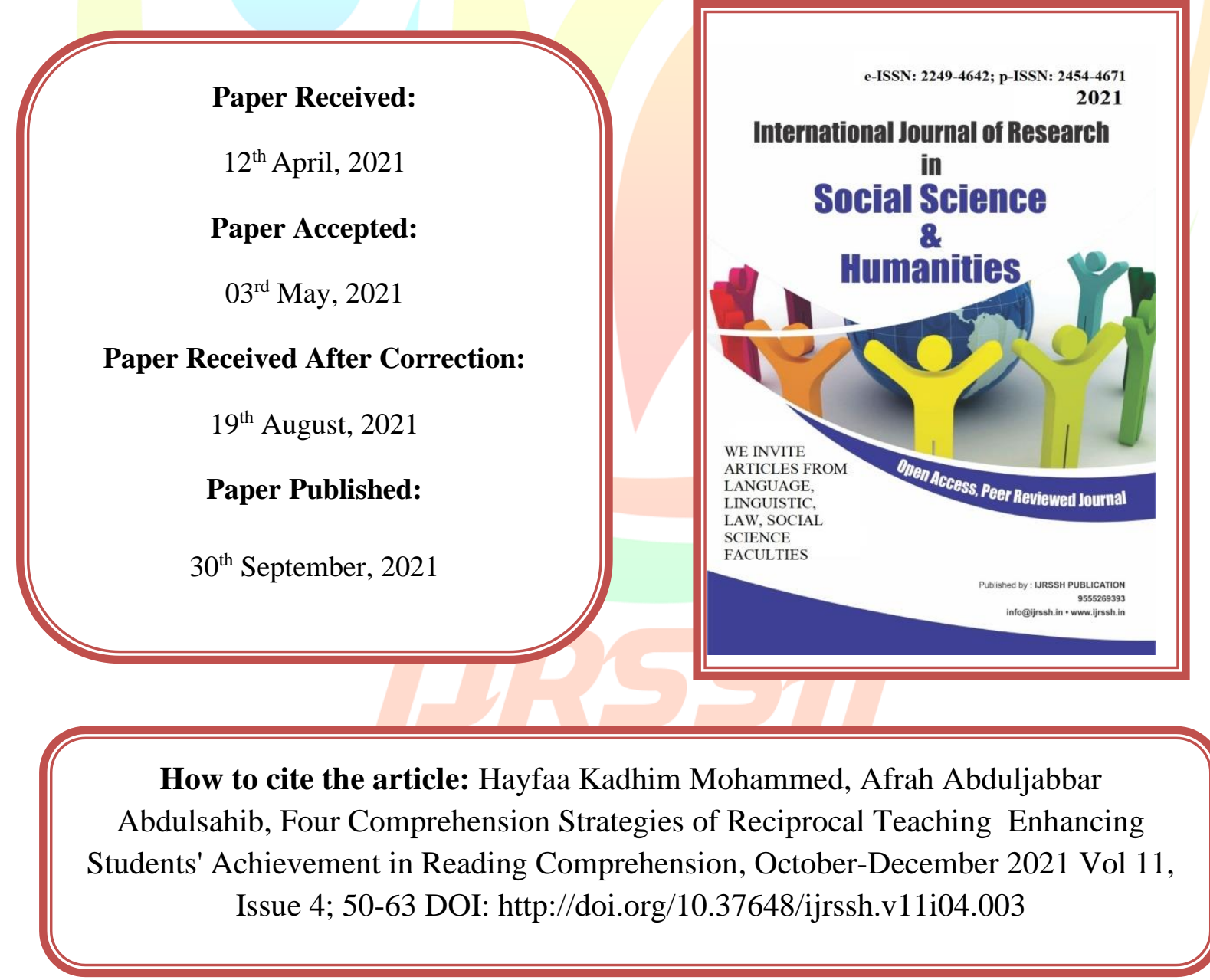




\title{
Volume: 11, Issue: 4, October-December 2021
}

\begin{abstract}
This study aims at finding out four comprehension strategies of reciprocal teaching enhancing students' achievement in reading comprehension. To achieve the aims of the study, null hypotheses have been put on after being subjected to experiment. Fifth stage of secondary school (female) students' in the city center of Masin, during the second term of the academic year 2017-2018. The sample of the study consists of (64) subjects, (32) students represent the experimental group, and (32) students represent the control group. While the control group has been taught by using " English for Iraq '5th preparatory SB, the experimental group has been taught by using four comprehension strategies of Reciprocal method. The researchers taught both the experimental group as well as the control group. The result of study shows that there is a statistically significant difference between the mean scores of the development of the experimental group taught by "Four Comprehension strategies of reciprocal method" of the pretest and the posttest.
\end{abstract}

Keywords: Reciprocal Teaching, Reading Comprehension 


\section{Volume: 11, Issue: 4, October-December 2021}

\section{INTRODUCTION}

\section{The Problem and Its Significance}

Many teachers are concerned with the amount of students that have difficulty with reading comprehension. Given that reading is a complex process, many students struggle with reading comprehension because they have a crack in their foundations of literacy. Educators must provide differentiated instruction for readers to help them. One evidence-based strategy that teachers can implement into the learning is the use of the reciprocal teaching strategy to model the cognitive process of reading.

The purpose of this study is to investigate whether the use of the reciprocal teaching will improve students with specific learning disabilities' scores on reading comprehension assessments. The goal of Reciprocal Teaching is flexible and independent use of all the strategies. Ultimately, students should become so familiar with the RT strategies that they use them in any situation, whenever they will be of help. From the beginning, the strategies should be used in any order that is appropriate to the text. Reciprocal teaching is an instructional activity that takes the form of a conversation between teachers and students taking into account parts of script for the purpose of building the meaning of it. Reciprocal teaching is a reading technique which is thought to promote students' reading comprehension. A reciprocal approach provides pupils with four precise reading strategies that are actively used to support comprehension: predicting, Summarizing, Clarifying, and predicting (Palincsar, 1986: 211).

Palincsar believes the purpose of reciprocal teaching is to simplify a group effort between teacher and students as well as among learners in the purpose of delivery meaning to the script. Reciprocal teaching is most effective in the context of small-group cooperative investigation, which is kept by the teacher or reading tutor.

\section{The Aim of the Study}

Finding four comprehension strategies of reciprocal teaching enhancing students' achievement in reading comprehension.

\section{The Hypotheses}

The following hypotheses were resulting from the main question:

1. There are statistically significant differences at $(\alpha>0.05)$ between students' mean scores of pre and post application of the achievement test of the experimental group in favor of post-test.

2. There are statistically significant differences at $(\alpha>0.05)$ between students' mean scores of the control group and the 


\section{Volume: 11, Issue: 4, October-December 2021}

experimental group in the achievement test in favor of experimental group.

\section{Value of the Study}

The value of the study is dedicated by the following facts:

1. The importance of investigating four comprehension strategies of reciprocal teaching enhancing students' achievement in reading comprehension.

\section{Limits of the Study}

The current research is limited to:

1- A sample of fifth stage of secondary school (female) students in the city center of Masin, during the second term of the academic year 2017-2018.

2- Reading comprehension, as established in the curriculum English For Iraq (unit 6.7.8.9) for control group and "Grammar In Context book "for experimental group

\section{Definition of the Terms}

\section{Reciprocal Approach}

The term "reciprocal" defines the nature of the connections each individual has in response to the others. This discussion is structured by the use of four strategies: questioning, clarifying, summarizing, and predicting. The teacher and learners take turns assuming the role of discussion leader

\section{Reading Comprehension}

Alderson (2000:128) defines reading as "... an enjoyable, intense, private activity, from which much pleasure can be derived, and in which one can become totally absorbed.

\section{Theoretical Background}

The reciprocal teaching method requires students monitor their reading comprehension. Strategies are used so that students comprehend better as they read various types of texts (Taylor, 1992: 39-48). According to Greenway 2002, the goal of reciprocal teaching is to make poor comprehends aware of how these strategies work, which ones to use and how to use them. For example, summarizing the main idea of a paragraph of text helps students not only to connect what they already know to this piece of text, but also to predict what might happen in the next paragraph to check their prediction"(Greenway, 2002: 114). In addition, students were learning to process a deeper understanding of the text (Lederer, 2000:91-106). 


\section{Volume: 11, Issue: 4, October-December 2021}

\section{Strategies of the Reciprocal Teaching Method}

There are four main metacognitive reading strategies of the reciprocal teaching method such as: predicting, questioning, clarifying, and summarizing to foster and monitor their reading comprehension as shown in figure 1

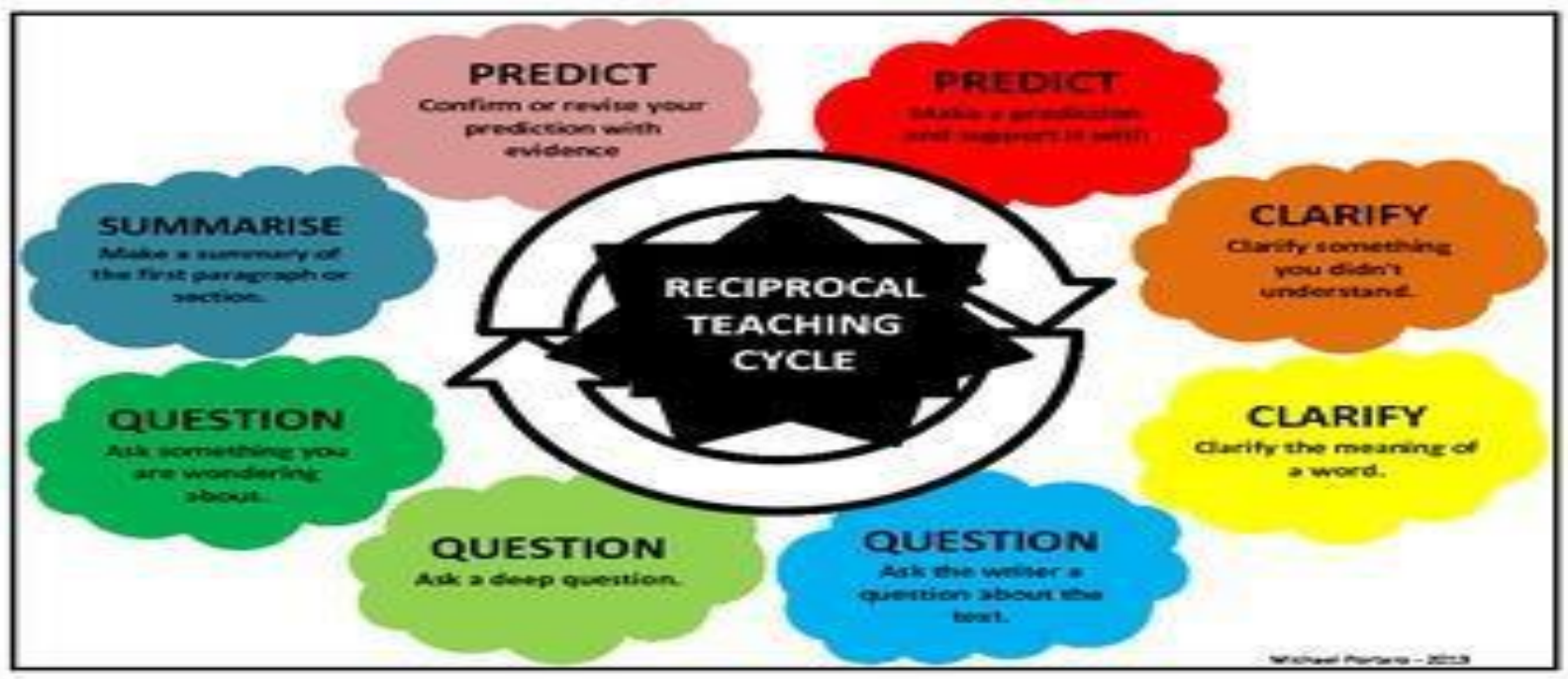

Figure 1: Four Main Metacognitive Reading Strategies of the Reciprocal Teaching by(Greenway, 2002: 114).

\section{$\underline{\text { Predicting }}$}

The prediction phase involves readers in actively combining their own background knowledge with what they have gathered from the text. With a narrative text student imagine what might happen next. With an informational text, students predict what they might learn or read about in subsequent passages. Predicting involves combining the reader's prior knowledge, new knowledge from the text, and the text's structure to create hypotheses related to the direction of the text and the author's intent in writing. Predicting provides an overall rationale for reading - to confirm or disconfirm self-generated hypotheses (Doolittle et al., 2006: 106-118).see figure 2. 


\section{Volume: 11, Issue: 4, October-December 2021}

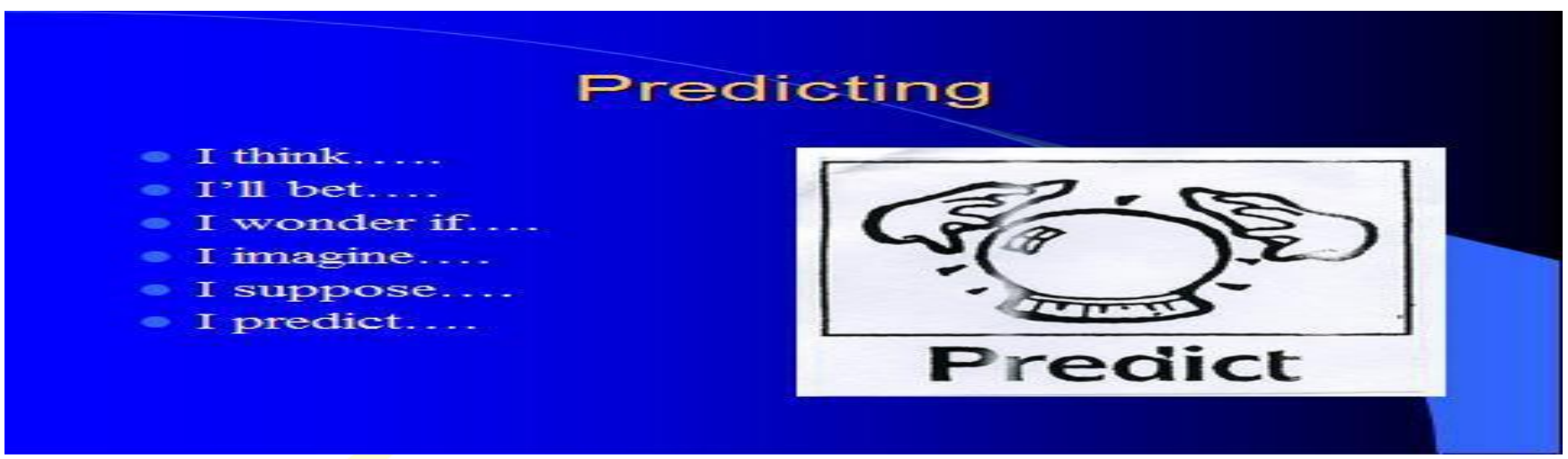

Figure 2: Predicting as first Metacognitive Reading Strategies of the Reciprocal Teaching by (Doolittle et al., 2006: 106-118

\section{Questioning}

When using the questioning strategy, readers monitor and assess their own understanding of the script by asking themselves questions. This self-awareness of one's own internal thought process is termed metacognition Questioning involves the identification of information, themes, and ideas that are central and important enough to warrant further consideration. The central or important information, themes, or ideas are used to generate questions that are then used as self-tests for the reader. Questioning provides a context for exploring the text more deeply and assuring the construction of meaning (Alfassi, 1997: 309 - 332 ) .See Figure 3

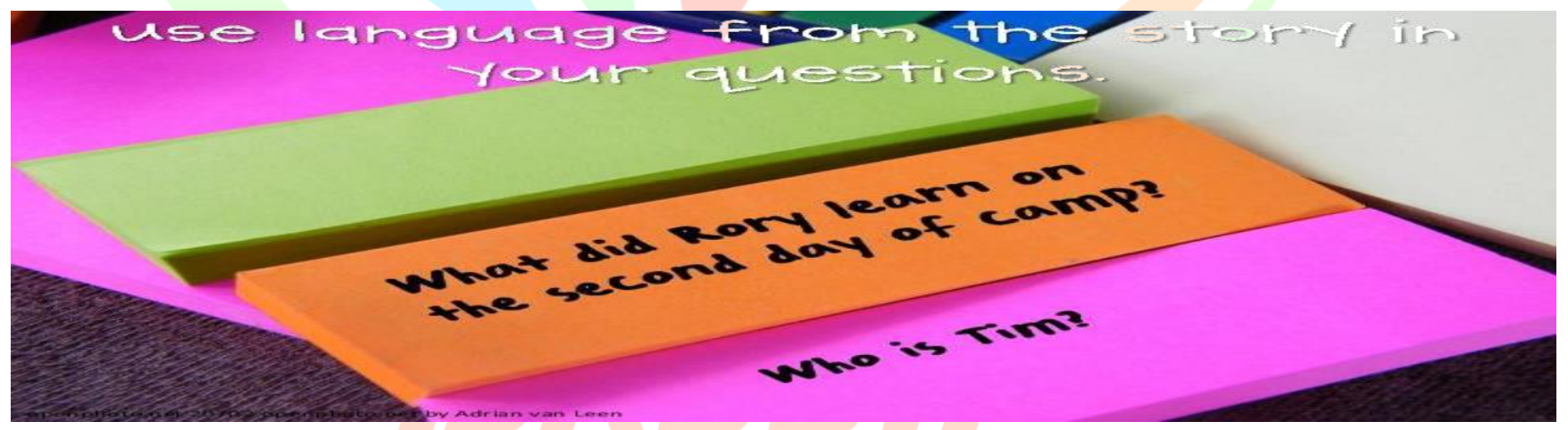

Figure 3: Questioning as the Second Metacognitive Reading Strategies of the Reciprocal Teaching by (Doolittle et al., 2006: 106-118). 


\section{Volume: 11, Issue: 4, October-December 2021}

\section{Clarifying}

The clarification strategy focuses on training students in specific steps to help with decoding (letter-sound correspondence, "chunking," spelling, etc.), as well as fix-up strategies to deal with difficult vocabulary and lapses in concentration. Clarifying involves the identification and clarification of unclear, difficult, or unfamiliar aspects of a text. These aspects may include awkward sentence or passage structure, unfamiliar vocabulary, unclear references, or obscure concepts. Also, Clarifying provides the motivation to remediate confusion through re-reading, the use of context in which the text was written and/or read, and the use of external resources (e.g., dictionary or thesaurus). The Clarifier will address confusing parts and attempt to answer the questions that were just posed (Rosenshine and Meister, 1994:121). See Figure4

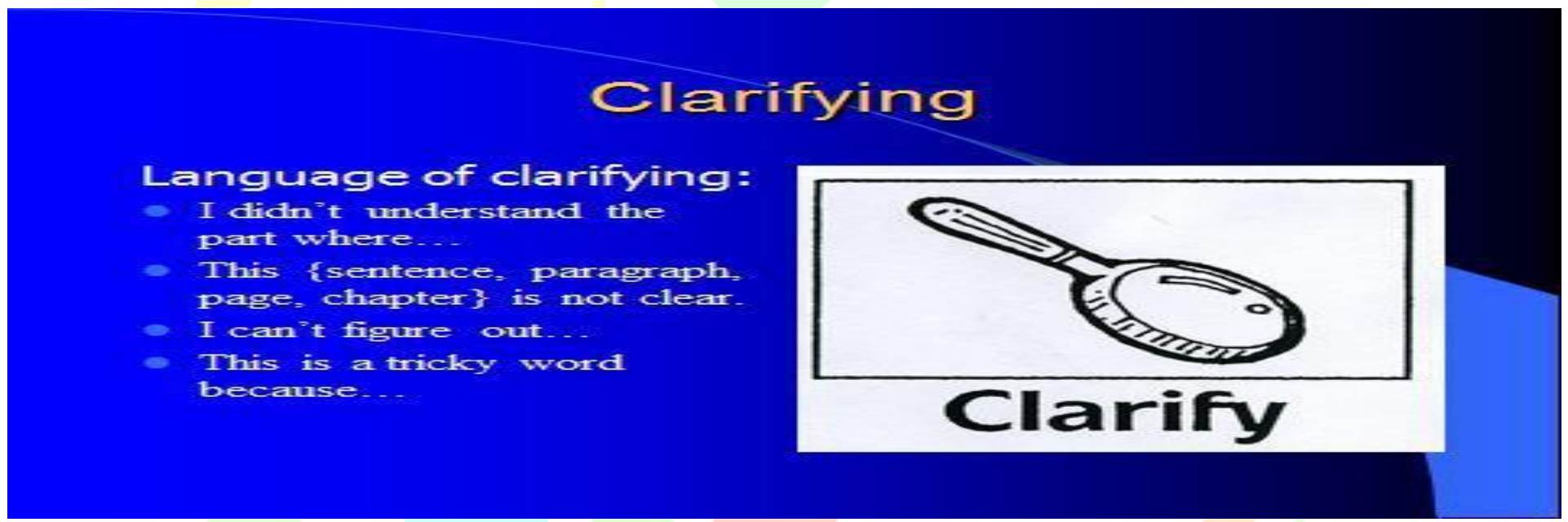

Figure 4: Clarifying as the third Metacognitive Reading Strategies of the Reciprocal Teaching by (Vacca, etal,.201: 89)

\section{Summarizing}

Summarization requires the reader to perform the task of discriminating between important and less-important information in the text. It must then be organized into a coherent whole (Palincsar and Brown, 1984). See Figure 5 


\section{Volume: 11, Issue: 4, October-December 2021}

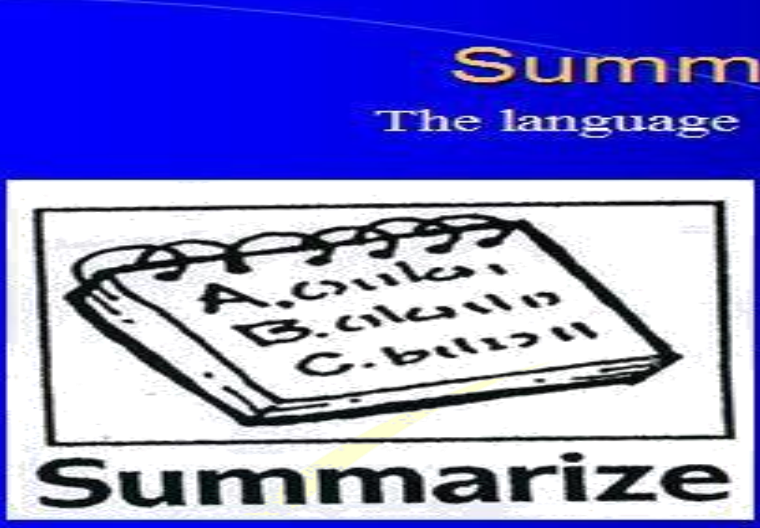

Summarizing

Of Summmanizing:

- The most important ideas in this text are.

- This part was about

- The book was about

- First.

- Next

- Then

- Finally

- The story takes place..

- The main characters are

- A problem occurs when

Figure 5: Summarizing as the Fourth Metacognitive Reading Strategies of the Reciprocal

Teaching by (Vacca, etal, .201: 89)

\section{METHODOLOGY AND PROCEDURES}

\section{Experimental Design}

In order to achieve the aim of this study, the researchers have used" Pre test- Post test Control Group Design", as shown in Table (1) is used as the experimental design needed to carry out the experiment of this study.

Table 1 The Experimental Design

\begin{tabular}{lccc}
\hline Experimental group & Pre Test & Independent Variable & Post Test \\
\hline \hline 2Control group & Pre Test & Post Test & \\
\cline { 2 - 3 }
\end{tabular}

Experimental group is taught by four comprehension strategies of reciprocal teaching, and the control group is taught by the traditional way. At the end of experiment, both groups are exposed to the post-test which has already been applied to find out which group is better in reading comprehension, i.e. to see the effect of the independent variable (four comprehension strategies of reciprocal teaching) on the dependent one( students' achievement in reading comprehension) . 


\section{Volume: 11, Issue: 4, October-December 2021}

\section{Population and Sample}

The population of this study consists of Fifth stage of secondary school (female) students' in the city center of Masin, during the second term of the academic year 20172018.The total number of those students is (104) female. The researchers randomly selected (64) to present the sample of this study. The sample is randomly distributed as follow: (32) students for the purpose of experimental group, (32) students for the purpose of the control. In order to increase the sensitivity of the experiment and thereby increase the probability of detecting the effect of such a variance, the researchers have equalized the experimental and control groups in age, parents' education level, and pre - test performance.

\section{Student's Pre-Test Performance}

The mean scores of the experimental group and the control one in previous knowledge concerning the material that would be taught during the experiment are (15.43) and (16.37) respectively. The computed $t$ - value is (1.20), which is below the $t$ - table value, which is (2.00). So there is no statistical significant difference between the two groups at (0.05) level of significance and (62) degrees of freedom. (See Table 2 and Appendix )

Table 2 the T - Value for the Students' Scores in the Pre - test

\begin{tabular}{lllllllll}
\hline Group & $\begin{array}{l}\text { Number of } \\
\text { subject }\end{array}$ & Mean & Variance & Df & $\begin{array}{l}\text { Computed } \\
\text { Value }\end{array}$ & $\begin{array}{l}\text { Tabulated } \\
\text { Value }\end{array}$ & $\begin{array}{l}\text { Level } \\
\text { significance }\end{array}$ \\
\hline Experimental & 32 & 15.43 & 9.60 & 62 & 1.20 & 2.00 & 0.05 & \\
Control & 32 & 16.37 & 9.66 & & & & & \\
\hline
\end{tabular}

\section{Pre-test and Post test}

Both experimental and control groups were given a pre-test before the presentation of the material to find out the mean score of both groups before receiving the treatment. After having the pre-test, the experimental group was taught by using (four comprehension strategies of reciprocal teaching), while the control group was taught by conventional method. Both of these groups were given the treatment in three months. After giving the treatment, the post test was given to each group. It was exactly the same as pre-test in terms of time and the contents. It was intended to find out the mean scores of experimental and control groups. 


\section{Volume: 11, Issue: 4, October-December 2021}

The Test

The researchers construct a test from (15) items. The test was in the form of multiple choice questions. The test was about students' ability in reading comprehension. The results of the scores of pre-test and post-test were used to see the improvement of students' reading comprehension skills after they were given the treatment. (See Appendix ). For more, a good test should be valid, reliable and usable.

\section{The Test Validity}

To be sure that the test has the face validity and content, it was exposed to a jury of ten members (see appendix ) who are asked to give their agreement, modification or any addition realties to the test. It is important to note that the prepost test is judged valid by all the of the jury's members, which means $90 \%$ agreement. In fact, all the members agreed on all items.

\section{The Test Reliability}

In this study, the test-retest method is used because it is the suitable one with the aim of this study. To determine whether the test of the present study is reliable or not, Pearson Correlation Coefficient formula is used. The method which is used to find the reliability of the test is re-test. The test was applied on 13th of September and 27th of October 2017. Fifteen days later, there was a re-test on the same sample. After calculating correlation coefficient between the first application degrees of test and the second application degrees by using Pearson correlation coefficient, it seemed that reliability coefficient for the two tests was (0.80) as reliability coefficient for reading comprehension respectively. Its high value clearly indicated the test reliability in measurement.

\section{ANALYSIS OF DATA}

\section{Comparison of Experimental and}

\section{Control Groups in the Post test Scores}

The result of this research shows that there is a difference of the output between both of groups, experimental and control groups, during the administration of the test (Pre- test and Post test). It can be seen in the table (3) below. 


\section{Volume: 11, Issue: 4, October-December 2021}

Table (3) The Mean Score of Pre-Test and Post- Test between Both Groups

\begin{tabular}{llll}
\hline No & Groups & Pre-Test & Post -Test \\
\hline $\mathbf{1 -}$ & Control & 16.37 & 16.37 \\
$\mathbf{2 -}$ & Experimental & 15.43 & 25.43 \\
\hline
\end{tabular}

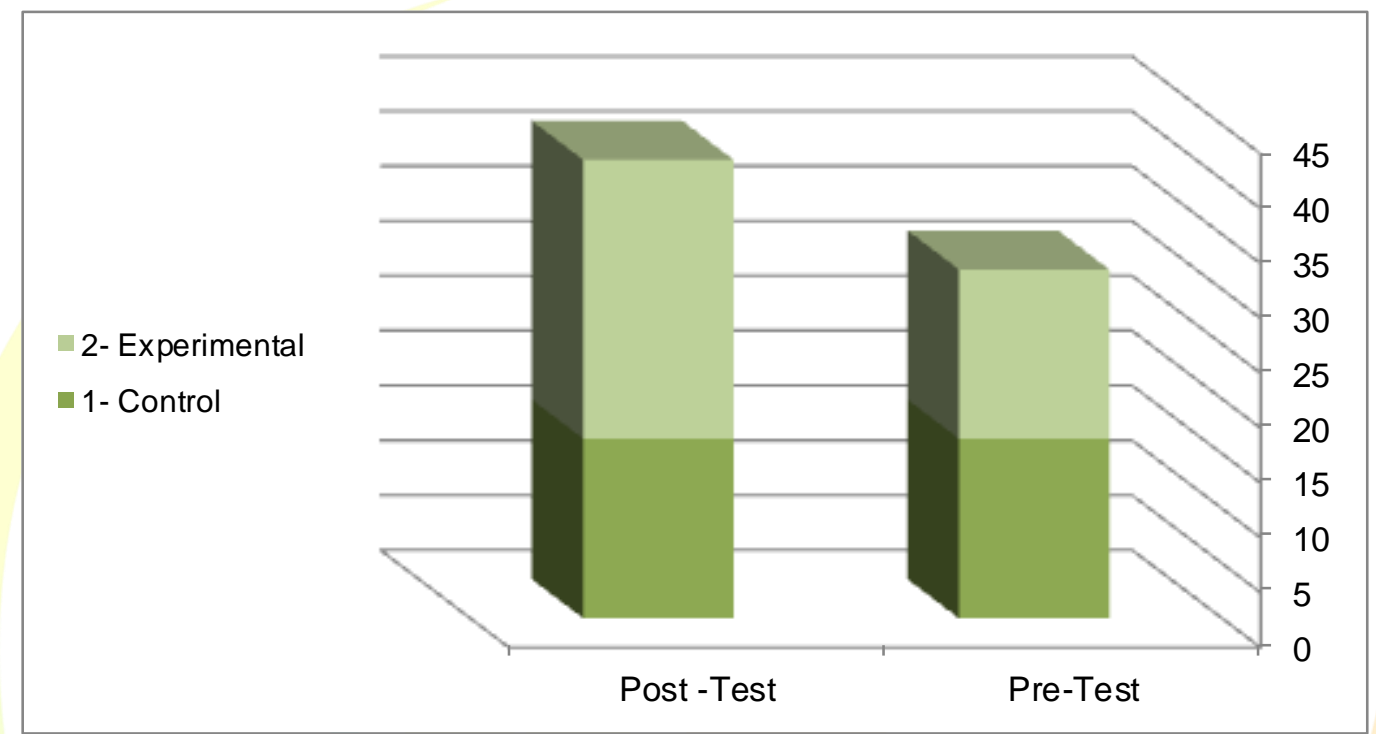

\section{Graphic (1) The Mean Score of Pre-Test and Post- Test between Both Groups}

Table (6) shows that the mean score between both groups increased from pre- test to post test. The mean score of control dose no group increased (16.37).There was no points increase in students' mean score between pre- test and post- test. While in experimental group, the results show that the mean score of experimental group is higher than in control group. The mean score of experimental group increased from (15.43) to (25.43) .There was (15) points increase in students' mean score between pre-test and post test. This difference takes place because the effect of different treatment on each group. The Experimental group was treated by (Four Comprehension strategies of reciprocal method) while in Control Group was treated without it. Moreover, the result of computing t-test shows that t-observed is higher than t-table as follows: 


\section{Volume: 11, Issue: 4, October-December 2021}

Table (4) The Results of the T-test Calculation

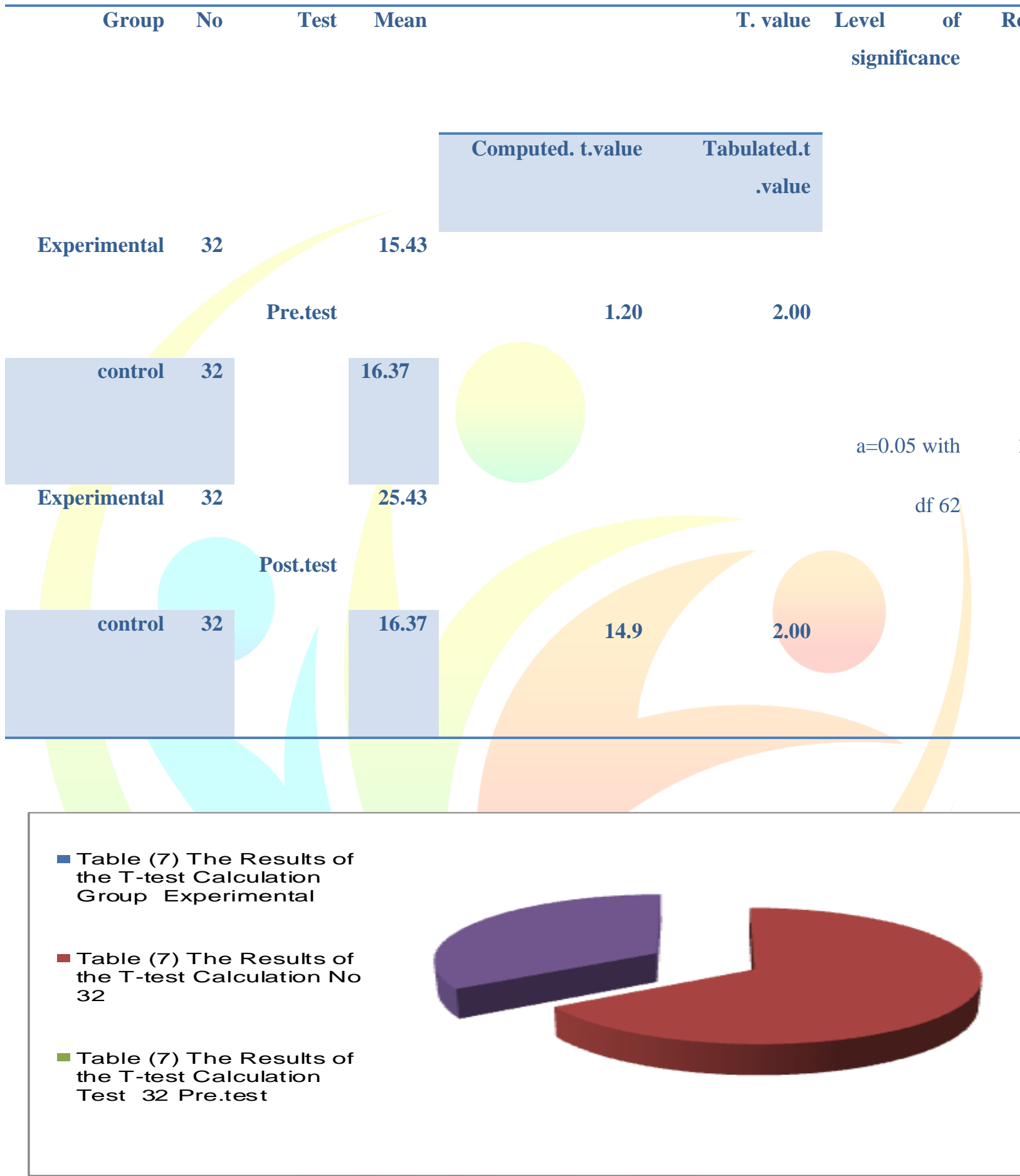

\section{Graphic (2) The Results of the T-test Calculation}

The calculation shows that the t-observed is higher than $t-$ table $(14.9>2.00)$ for the degree of freedom df (62) at level of significance $\alpha=0.05$. Therefore, alternative hypothesis (Ha) is accepted and null hypothesis (Ho) is rejected. It means that "there is a significant effect of applying (Four Comprehension strategies of reciprocal method) on students' reading comprehension". 


\section{Volume: 11, Issue: 4, October-December 2021}

\section{Conclusions}

It is concluded that:

1. Using (Four Comprehension strategies of reciprocal method) in teaching reading comprehension has many benefits; it enables the students to be more familiar with learning reading skills in comprehension, give them chance to think, and reduces some difficulties that face students during learning reading comprehension. The (Four Comprehension strategies of reciprocal method) is vital in giving the student the opportunity to look at the text more deeply.

2.Reciprocal teaching can help students become more conscious of metacognitive strategies through explicit instruction with social interaction, so they can learn gradually and control their own learning process.

\section{Recommendations}

1. The English teacher should apply (Four Comprehension strategies of reciprocal method) strategy in teaching reading comprehension.

2. The students use the (Four Comprehension strategies of reciprocal method) in order to improve their reading comprehension.

3. Before applying (Four Comprehension strategies of reciprocal method) strategy the teacher should prepare himself or herself and the material well in making students' awareness of thinking about the topic by asking themselves questions.

\section{Suggestions}

1. A study can be replicated in order to develop the students' reading by using (Four Comprehension strategies of reciprocal method) in other stages.

2. A study can be done in order to develop the students' reading by using (Four Comprehension strategies of reciprocal method) in other Subjects. 


\section{Volume: 11, Issue: 4, October-December 2021}

\section{REFERENCES}

1. Alfassi, Miriam (1998) Reading for meaning: The efficacy of reciprocal teaching in fostering reading comprehension in high school students in remedial reading classes. American Educational Research Journal.

2. Alderson, J.C. (2000) Assessing Reading. Cambridge, C.U.P.

3. Brown, A. L. (1980) Metacognitive development and reading. Hillsdale, NJ: Erlbaum

4. Doolittle, P.E., Hicks, D., Triplett, C.F., Nichols, W.D., and Young, C.A. (2006) Reciprocal teaching for reading comprehension in higher education: A strategy for fostering the deeper understanding of texts. International Journal of Teaching and L.H. E.

5. Greenway, C. (2002) The process, pitfalls and benefits of implementing a reciprocal Teaching intervention to improve reading comprehension of a group of year 6 pupils. Educational Psychology in Practice.

6. Lederer. (2000) Reciprocal teaching of social studies in inclusive elementary classrooms. Journal of Learning Disabilities, 33(1), 91-106.Prentice Hall.

7. Palincsar, A. S. (1986) Reciprocal teaching. In Teaching reading as thinking. Oak Brook, IL: North Central Regional Educational Lab.

8. Taylor, B., \& Frye, B. (1992). Comprehension strategy instruction in the intermediate grades. Reading Research and Instruction, 32 (1),

9. Vacca, R.T.,Vacca, J.L., and Mraz, M. (2011) Content area reading: Literacy and learning across the curriculum. Boston, MA: Pearson Education Inc. 